\title{
DERECHO AL HONOR VS. MEDIOS DE COMUNICACIÓN: UNA PROPUESTA DE SOLUCIÓN DESDE LA PONDERACIÓN
}

\section{RIGHT TO HONOR VS. MEDIA: A SOLUTION PROPOSAL FROM A LEGAL WEIGHING APPROACH}

RESUMEN: El artículo se propone fundamentar la solución de las posibles colisiones entre el derecho al honor y los derechos asociados a los medios de comunicación; para ello se emplean los métodos de análisis jurídico doctrinal e histórico jurídico. Se concluye que el despliegue de los derechos asociados a los medios de comunicación (libertad de prensa y expresión, y derecho a la información), y el desarrollo tecnológico de dichos medios, ha posibilitado la divulgación masiva de informaciones y opiniones, que cuando son erradas o no contrastadas, tienden a vulnerar el derecho al honor de personas e instituciones, contribuyendo a formar sobre éstas estados de opinión socialmente reprobables. Esta situación se ha resuelto mediante reglas de ponderación e inaplicación, en la vía judicial, luego de la aparición del conflicto; y a través de garantías previsoras, como la instrumentación de los derechos adscriptos de respuesta y rectificación.

PALABRAS CLAVES: derecho, honor, medios de comunicación.

ABSTRACT: The article proposes to base the solution of the possible collisions between the right to honor and the rights associated with the media; to this end, legal doctrinal and historical legal analysis methods are used. It is concluded that the deployment of the rights associated with the media (freedom of the press and expression, and the right to information), and the technological development of said media, has made possible the massive dissemination of information and opinions, which when they are wrong or not contrasted, tend to violate the right to honor people and institutions, helping to form on these socially reprehensible opinion states. This situation has been resolved by means of weighting and nonapplication rules, in the judicial way, after the appearance of the conflict; and through anticipatory guarantees, such as the implementation of rights attached to the response and rectification.

KEY WORDS: right, honor, media.

\footnotetext{
${ }^{1}$ Licenciado en Derecho, Licenciado en Historia, Máster en Ciencias de la Educación, Máster en Derecho Constitucional y Administrativo, Doctor en Ciencias. Profesor Titular de Teoría General del Estado y de Teoría del Derecho de la Universidad de Pinar del Río, Cuba.
} 


\section{INTRODUCCIÓN}

El hombre, desde tiempos inmemoriales, se ha preocupado por la consideración y estima que recibe de la sociedad, así como de su autoestima; estas proyecciones de su personalidad conforman su honor. Históricamente, la protección del derecho al honor se ha regulado en las ramas penal o civil, pero en tiempos recientes se ha plasmado en las Constituciones como un derecho fundamental. El despliegue de los derechos asociados a los medios de comunicación (libertad de prensa y expresión, y derecho a la información), y el desarrollo tecnológico de dichos medios, ha posibilitado la divulgación masiva de informaciones y opiniones, que cuando son erradas o no contrastadas, tienden a vulnerar el derecho al honor de personas e instituciones, contribuyendo a formar sobre éstas estados de opinión socialmente reprobables.

Este trabajo tiene como objetivo reflexionar teóricamente sobre el derecho al honor y las posibles contradicciones que se generarían con los derechos asociados a los medios de comunicación, así como las soluciones que se proponen para resolverlas. Para el cumplimiento del objetivo los autores se apoyaron en el empleo de los métodos de análisis jurídico doctrinal e histórico jurídico.

\section{REFERENTES DOCTRINALES DEL DERECHO AL HONOR}

Cuando alguien se refiere al honor de una persona, generalmente, hace alusión al reconocimiento o estimación social del que ésta goza. La sociedad impone determinadas normas o exigencias sociales a sus miembros, y a través de la valoración social e individual enjuicia permanentemente la conducta de los sujetos, premiándolos con la aceptación o sancionándolos con el rechazo.

El Diccionario Filosófico de M. Rosental y P. Iudin define el honor como "Categoría moral; que expresa el reconocimiento, por parte de la sociedad, de todo cuanto merece una alta estimación en la manera de actuar de un individuo, de una colectividad, de una institución..." (Rosental y Iudin, 1981, p. 223) y luego, asumiendo a juicio del autor una posición reduccionista, identifica al linaje como causa del honor en el feudalismo, a la 
posesión de riquezas como causa del honor en el capitalismo, y a los méritos ante el pueblo como causa de honor en el socialismo. Si este planteamiento tiene algo de veraz, no es toda la verdad, pues las absolutizaciones son negativas para cualquier pretensión científica.

El honor también es definido como una cualidad moral vinculada al cumplimiento del deber, la virtud, el mérito y el heroísmo. Se manifiesta en el ámbito familiar, laboral y social a través de la fama, la gloria o simplemente mediante la buena opinión de la que se disfruta. Generalmente el honor es visto como un factor para obtener de la sociedad favores materiales o espirituales, como buenos empleos, riqueza personal o estatus social.

Para algunos autores la dignidad humana es vista como la suma de caracteres o cualidades que configuran ante las personas la existencia de un determinado ser y no otro, como identidad de dicho ser entre los hombres; como un conjunto de rasgos que sumados unos a otros confirmarían la pertenencia de un ser dado a la especie humana. Por lo tanto, la dignidad humana se encuentra en el fundamento del derecho al honor.

Para el constitucionalista Eduardo Espín "El honor, en tanto que aprecio y estima que una persona recibe en la sociedad en la que vive, es un derecho fundamental que afecta íntimamente la dignidad de la persona." (López Guerra y otros, 2000, p.146). Obsérvese que en esta definición sobresalen los términos aprecio y estima, entendidos como consideración que tiene la sociedad de una persona en un sentido objetivo, a la vez que manifiesta una vinculación de estas categorías con la dignidad de la persona.

De lo expresado se desprende que el derecho al honor sería como una derivación, como emanación de la dignidad humana, entendido por ello como derecho a ser respetado por las demás personas. Sin embargo, el derecho al honor tiene un carácter autónomo e independiente de otros similares como el derecho a la intimidad y a la propia imagen, aunque erradamente se les confiera el mismo tratamiento jurídico por los autores y las normas del derecho positivo.

Autores especializados en las Ciencias Penales han logrado identificar la diferencia sustancial entre la intimidad y el honor por vía de la determinación del bien jurídico que se protege en cada caso. El bien jurídico "intimidad" lo definen como libertad potenciada en el ámbito de lo íntimo, constituida por las costumbres, hábitos y modos privados de asumir la convivencia humana, en lo personal y familiar, en su índole cultural y espiritual; es la libertad personal de asumir la vida fuera de las obligaciones sociales. Mientras que el bien jurídico 
conformado por el derecho al honor lo definen como el patrimonio moral que le corresponde a cada persona.

Otros autores enfatizan en la relación cuasi conflictual que se puede establecer entre los derechos al honor y la dignidad, y el derecho a la libertad de expresión. Al respecto plantean Blas Guerrero y García Cotarelo:

El derecho al honor, la intimidad personal y familiar y la propia imagen constituyen un claro límite a la libertad de expresión...Se estima en todo caso que esa protección no cubrirá los hechos de dominio público, aquellas circunstancias personales que el interesado, a través de su comportamiento, no considerada de naturaleza reservada o cuando los hechos objeto de información...afectan exclusivamente a actividades que tengan relación directa con las causas de proyección pública de la persona afectada. (Blas Guerrero y García Cotarelo, s/f, p. 209).

La dignidad humana y el honor son contenidos de las relaciones sociales que han estado presentes desde el origen de la humanidad, como se ha referido. Ambas categorías tienen una fuerte trascendencia tanto para la moral como para el Derecho; desde sus primeras manifestaciones se trataba de normas morales que llegaron a tener efecto jurídico. Esto se valida porque el honor se refiere a un modo de conducta, que de corresponderse con las exigencias sociales, se retribuye mediante la adquisición de determinados derechos, siendo el más común el derecho al buen nombre.

Reflexionando sobre la naturaleza jurídica del concepto honor se puede apreciar tres posiciones teóricas: la que se concibe desde un punto de vista subjetivo, refiriéndose a la autoestima producto de la autovaloración que tiene una persona sobre sí misma; la objetiva, que refiere a la consideración que tiene la sociedad sobre una persona, a partir de valorar su conducta, o el cumplimiento de las normas establecidas a nivel social.

Los autores se refieren a una posición teórico doctrinal intermedia, la cual consideran más contemporánea y por ello aceptada; esta

concibe el honor desde un punto de vista cultural, como el resultado del juicio de los miembros de la comunidad sobre el comportamiento de una persona con relación a sus deberes o como derecho coincidente con la dignidad propia de la condición humana, en virtud de la cual todos los seres humanos gozan de la facultad de ser respetados por los demás. (Colectivo de autores, 2005, 171).

El honor suele vincular a las personas con elementos que conforman la estructura de la sociedad, o por lo menos con ramas de la actividad humana y con los oficios y profesiones. En este sentido se reconoce la existencia del honor profesional, comercial, científico u otros. 
Otra arista interesante es analizar que tratamiento han dado las diferentes ramas o materias del Derecho al honor. Se percibe en este sentido una expresión trilateral o tridimensional del referido derecho: en la materia constitucional se concibe como derecho fundamental; en el Derecho Civil como derecho subjetivo de la personalidad, y en Derecho Penal como bien jurídico.

La complejidad para designar al reportorio de derechos dentro del que se considera el derecho al honor es tal, que incluso, en el Derecho Constitucional y en los tratados internacionales aparecen otras designaciones como derechos humanos, libertades individuales y derechos del hombre.

El constitucionalista español Pérez Tremps atribuye esta diversidad de designaciones en el Derecho Constitucional a varios motivos, que van desde la perspectiva metodológica con que se analiza una misma realidad jurídica, pasando por la dimensión histórica, hasta llegar a la estructura interna de los distintos derechos.

A pesar de esta diversidad de designaciones, el autor coincide con Pérez Tremps cuando plantea

$$
\begin{aligned}
& \text { desde el puno de vista constitucional, el concepto de «derechos } \\
& \text { fundamentales» resulta el más adecuado; ello porque, por otra parte, la } \\
& \text { expresión «derechos fundamentales» sirve para poner de manifiesto la } \\
& \text { naturaleza especial que dichos derechos poseen: su consideración como } \\
& \text { elemento básico y preeminente del ordenamiento, frente a la naturaleza } \\
& \text { «ordinaria» que los demás derechos subjetivos poseen. (López Guerra y } \\
& \text { otros, 2000, p. 73) }
\end{aligned}
$$

También debe considerarse que la doctrina y la legislación constitucional emplean el término derechos fundamentales en dos sentidos: uno amplio, y considerado técnicamente incorrecto por algunos autores, que le atribuye tal calificativo a cualquier derecho plasmado en la Constitución; y uno estricto, reservado para aquellos derechos que conforman el núcleo central del estatus jurídico del individuo. Estos derechos son los que en Constituciones como la española manifiestan una especial rigidez exigida para su reforma, y gozan de un reforzado sistema de garantías normativas en las leyes de desarrollo.

Autores como el español Pérez Luño definen los derechos fundamentales como "el conjunto de facultades, instituciones y prerrogativas que en cada momento histórico concretan la exigencia de la dignidad, la libertad y la igualdad humanas, las cuales deben ser reconocidas positivamente por los ordenamientos jurídicos...” (Pérez Luño, 1994, p. 44). 
Para Villabella Armengol los derechos fundamentales son aquellos dentro de los mismos derechos constitucionales y humanos, que además de positivarse han logrado que se les instrumenten vías garantistas seguras para su defensa e implementación. (Villabella Armengol, 1991, p. 91)

Por su parte, el Derecho Civil concibe los derechos subjetivos de la personalidad como el poder jurídico o el conjunto de facultades conformadoras de una unidad que un ordenamiento jurídico otorga a una persona, a la que por ello se le permite un determinado comportamiento o se le concede la oportunidad de exigir de otra una prestación o una conducta debida, siempre para la consecución de ciertos fines lícitos." (Valdés Díaz, 2005, p. 134).

El bien jurídico es para el Derecho Penal una relación social dinámica, que expresa la posición de los sujetos intervinientes en dicha relación, sus formas de vincularse entre sí y con los objetos de la realidad, en el trascurso del desarrollo histórico y en un contexto determinado.

La expresión trilateral del derecho al honor en un ordenamiento jurídico puede crear relaciones contradictorias, como la declaración en materia constitucional del carácter irrenunciable de los derechos fundamentales, y la posibilidad en sede penal de renunciar a iniciar un proceso por la vulneración del referido derecho por parte de su titular, en virtud de que dichos delitos son perseguibles a instancia de la parte afectada. Estas contradicciones pueden evidenciar situaciones de falta de unidad regulatoria, de integridad y de sistematicidad en un ordenamiento jurídico determinado.

Se coincide con la profesora Valdés Díaz cuanto expresa: “...los conceptos de honor, dignidad o fama no son inmutables... su contenido no es el mismo en todas las épocas; cada formación económico social imprime determinadas exigencias o patrones. Son categorías de marcado carácter social, de modo que varían con frecuencia.” (Valdés Díaz, 2005, p. 145).

De las teorías analizadas se puede deducir que el derecho al honor es la facultad que todo ser humano tiene de ser considerado y estimado por la sociedad (sentido objetivo), así como de autoestimarse a sí mismo (sentido subjetivo), lo cual es inherente a la condición humana, es un producto del progreso de la humanidad, y aunque su positivación no es un requisito previo de existencia, es una de las formas más seguras de garantizar dicho derecho. 


\section{LOS MEDIOS DE COMUNICACIÓN MASIVA, LA LIBERTAD DE PRENSA Y EL DERECHO A LA INFORMACIÓN}

Desde la antigüedad el hombre ha sentido la necesidad de comunicarse, para ello ha creado sus propios medios, utilizando en los inicios los que le ofrecía la naturaleza, y luego construyendo otros más sofisticados, derivados de su desarrollo intelectual. Primero se utilizaban los mensajeros humanos, así como a los animales domesticados; luego se emplearon el fuego, el humo y el reflejo de la luz solar, para crear señales visibles a grandes distancias.

La construcción de barcos, carruajes, y el empleo de caballos y otros animales de tracción permitieron alargar las distancias, ampliar los contactos, así como acelerar flujos comunicativos. Pero no se puede hablar todavía de medios de comunicación masiva hasta la creación de la imprenta moderna por Johannes Gutenberg, en 1440, técnica que permitió masificar los destinatarios del mensaje.

Por ello, los medios de comunicación masiva se basan en inventos de la modernidad; además de la imprenta, se desarrollan con la construcción de modernas vías, la autopropulsión del transporte, y las nuevas tecnologías para la transmisión de mensajes. A los efectos de esta investigación, los medios de comunicación deben ser entendidos como medios de masa o masivos, por el alcance de sus contenidos a gran cantidad de personas.

Danis McQuail define a los medios de comunicación de masas como "las tecnologías organizadas que posibilitan la comunicación de masas.” (McQuail, 1985, p.26). En su definición es fundamental la dimensión tecnológica, el carácter organizado, su papel de condición material para producir mensajes, y el carácter masivo de los destinatarios.

Para dicho autor los medios de comunicación de masas se concretan en la prensa escrita, la radio y la televisión. Plantea que la trascendencia de los medios deriva de que estos se constituyen en recursos de poder, pues son instrumentos potenciales de influencia, control e innovación en la sociedad; también son ámbito o esfera de desarrollo de la vida nacional e internacional; son una fuente importante de definiciones e imágenes; fuente primaria de la fama; y el origen de un sistema de significados. (McQuail, 1985, pp. 27 y 28)

Debe destacarse el importante papel que se le reconoce a los medios como fuente primaria de fama, que McQuail atribuye a los famosos, pero hay que señalar, a los efectos de 
esta investigación, que es extensivo a cualquier sujeto, pues la fama es resultado o efecto de la propia publicidad que produce el medio. En otro sentido, la fama es un concepto neutral, pues puede ser de valor socialmente positivo o socialmente negativo.

Esta potencialidad de los medios de producir fama (positiva o negativa), es la que fundamenta que el honor, entendido como derecho a la autoestima y a la consideración y estima de la sociedad, debe protegerse ante las actuaciones lesivas de los medios de comunicación; es decir, debe evitarse acciones de comunicación masiva que afecten injustamente la expectativa que cada cual tiene de ser considerado y estimado por los demás y por sí mismo.

Uno de los significados que atribuye McQuail a la comunicación de masas es que “... se puede considerar uno de los diversos procesos de comunicación a escala de toda una sociedad, que se encuentra en el vértice de una distribución piramidal de todos los procesos de comunicación.” (McQuail, 1985, p.35).

La definición aporta tres interesantes elementos: la comunicación de masas es un proceso, este proceso ocurre a nivel de toda la sociedad, y en su forma de expresión más general está por encima y a la vez contiene otros procesos de comunicación a escala menor. Estas tres características o particularidades de la comunicación de masas revelan el efecto masivo que puede tener una actuación mediática lesiva al honor, y por lo tanto al derecho que todos tienen a ser considerados y estimados socialmente.

García Fajardo, por su parte, entiende por medios masivos a las instituciones que intervienen en el proceso de interacción entre un emisor único (o comunicador) y un receptor masivo (o audiencia); un grupo numeroso de personas que cumpla simultáneamente con tres condiciones: ser grande, ser heterogéneo y ser anónimo. (García Fajardo, 1992, p. 23).

El propio McQuail, superando su definición tecnológica de los medios de comunicación de masas, reconoce su dimensión institucional. Al respecto plantea que un medio masivo: "Consiste, a grandes rasgos, en el conjunto de las organizaciones y actividades mediáticas junto con sus normas, formales e informales, de funcionamiento $\mathrm{y}$, ocasionalmente, los requisitos legales y éticos establecidos por la sociedad...” (McQuail, 1985, p. 42). 
Esta definición enfatiza en el papel de las normas, siendo trascendente para el objeto de la investigación en curso las formales; así como el ámbito de los requisitos legales para el funcionamiento institucional de los medios masivos.

En el sentido señalado McQuail enfatiza como característica de los medios que:

"La institución mediática se encuentra en la esfera pública, lo que significa, en particular, que está abierta a todos, como emisores o receptores; los medias tratan asuntos públicos con fines públicos, sobre todo cuestiones susceptibles de influir en la formación de la opinión pública; los media son responsables de sus actividades ante la sociedad (esta responsabilidad se expresa mediante leyes, regulaciones y presiones por parte del Estado y de la sociedad).” (McQuail, 1985, pp. 42 y 43).

Este planteamiento expresa dos características de especial incidencia para el derecho al honor frente a los medios de comunicación: el carácter abierto de los medios a los emisores y receptores, y su capacidad para influir en la formación de la opinión pública.

Los planteamientos de McQuail son expresión de la integración de las teorías de los efectos y las teorías normativas sobre los medios de comunicación (de "responsabilidad", “democrática" y "de participación comunitaria"), las cuales postulan que los medios de comunicación tienen efectos inmediatos y masivos sobre los públicos, por lo que requieren de una regulación sustentada en la responsabilidad, así como la participación de dichos públicos en el control de los mensajes. Especialmente sensible es ese control si contribuye a la formación de una opinión pública veraz y contrastada.

Se plantea que la primera ley sobre libertad de prensa fue aprobada en el Reino de Suecia el 2 de diciembre de 1766. En fecha posterior, los Bill of Rights del Estado de Virginia, de 1776, planteaban: "La libertad de prensa es uno de los baluartes más poderosos de la libertad, y sólo los gobiernos despóticos pueden ponerle trabas." (López de Ramón, 2014, p. 11). Por su parte, la Declaración de Derechos del Hombre y del Ciudadano, documento programático de la Revolución francesa de 1789 expresaba: "la libre comunicación del pensamiento y de las opiniones es uno de los derechos más preciosos del hombre. Todo ciudadano puede hablar, escribir e imprimir libremente, sin perjuicio de que responda de esta libertad en los casos determinados por la ley.” (Martín de la Guardia, 2008, p. 10). 
Dándole continuidad a la anterior evolución, la Primera Enmienda de la Constitución de los Estados Unidos de América, aprobada en 1791, plasmaba: "El Congreso no legislará respecto al establecimiento de una religión o la prohibición del libre ejercicio de la misma; ni pondrá cortapisas a la libertad de expresión o de prensa..." (La Constitución de los Estados Unidos de América, con nota explicativa, 1999, p. 45). En diferentes traducciones de este texto se emplean indistintamente los términos "libertad de palabra", "libertad de imprenta" o "libertad de prensa", expresiones que han tenido un significado específico y diferente en la teoría constitucional hispanoamericana. Sin embargo, gracias a las interpretaciones de la Corte Suprema de los Estados Unidos, esta enmienda se ha identificado usualmente con la libertad de prensa, sobre todo en el sentido de libertad de iniciativa empresarial periodística.

Para la doctrina liberal la libertad de prensa es concebida como el conjunto de garantías que permite a los ciudadanos ejercer el derecho de organizarse para fundar medios de comunicación, cuyos contenidos, en principio, no estén controlados ni censurados por el Estado. Con el tiempo el concepto ha extendido esta restricción de censura y control a otros actores políticos y de la sociedad civil, a la vez que se ha suscitado el debate sobre la pertinencia de establecer límites y restricciones a dicha libertad.

En general, el término libertad tiene diferentes definiciones en la doctrina jurídica, sin embargo, también se aprecian grandes puntos de coincidencia. Para Esteban Echevarría significa “...el derecho que cada hombre tiene para emplear sin traba alguna sus facultades en el conseguimiento de su bienestar, y para elegir los medios que puedan servirle a este objeto.” (Echevarría Espinosa, 1940, p. 165). No obstante, este autor reconoce un límite universal a dichos derechos: el derecho de los demás.

Juan Bautista Alberdi señalaba que “...la libertad es el poder de que cada hombre está dotado por su naturaleza para ejercer todas las facultades de su ser. Es la libertad social. Pero la condición de vida de la libertad de cada hombre es la libertad de los demás... la libertad es el respeto del hombre al hombre. La libertad es poder, autoridad. Respetar la libertad de cada hombre es respetar el poder, la autoridad de cada hombre. Respetar la autoridad unida o colectiva de todos los hombres que forman una sociedad es respetar la libertad de cada uno. E1 que no sabe obedecer no sabe ser libre.” (Alberdi Aráoz, 1920, p. 230). Este planteamiento, aunque de clara inspiración iusnaturalista, encierra un matiz de limitación social o estatista a los derechos de libertad. 
El legislador y profesor argentino Alfredo Lorenzo Palacios expresó que "la libertad no es un don que se recibe como beneficio gratuito, sino un deber que se cumple. Hemos de saber que la libertad que sólo da derechos, es absurda y peligrosa. La libertad está preñada de deberes, y para conquistar el orden, hay que establecer el equilibrio entre la autoridad y la libertad." (Palacios, 1939, p. 163). Esta postura cuestiona la libertad como mera inacción del Estado, e introduce tempranamente la concepción de la interdependencia entre derechos fundamentales y deberes ciudadanos.

Para Gregorio Badeni: "La libertad es una idea global comprensiva de la actividad humana que se desenvuelve en el ámbito privado y social. Es, sustancialmente, un concepto individual que se traduce en una fuerza, en una energía que dispone el hombre para crear y ejecutar sus ideas con absoluta independencia. Para colmar sus aspiraciones y el logro de su personalidad de acuerdo con las metas establecidas en su pensamiento." (Badeni, 2006, p. 442).

Esta definición, con acentuada influencia idealista, encierra un conjunto de categorías de amplio contenido axiológico. Especial mención requieren los términos "fuerza" y "energía" para "crear" y "ejecutar sus ideas". La propia naturaleza de dichos conceptos, jurídicamente indeterminados, expresa no obstante una intencionalidad ética e ideológica, de claro sabor liberal, en cuanto a contención de una intervención estatal no deseable.

Pero el propio autor matiza su posicionamiento inicial con las siguientes expresiones:

"Ese concepto individual se proyecta sobre la vida social generando las libertades civiles y políticas que, al desenvolverse en un marco de convivencia, están sujetas a una reglamentación razonable emanada del poder político. El concepto individual de libertad se traduce así en un valor jurídico social que la organización política debe preservar y coordinar.

Ese valor jurídico social presupone un orden normativo y una seguridad. Un orden normativo que diseñe los amplios espacios para el desarrollo armónico de las libertades individuales, y una seguridad jurídica traducida en las garantías tutelares de la actividad del ser humano." (Badeni, 2006, p. 442).

Hay en la segunda parte de la reflexión de Badeni una especie de conciliación entre iusnaturalismo y positivismo jurídico, pues reconoce el papel del Estado en el establecimiento de los límites a las libertades civiles y políticas, como requisito para un adecuado desenvolvimiento del hombre en su convivencia. Aquí la seguridad jurídica y las garantías 
tuteladas por el poder público político evidentemente vienen de la mano de su positivación normativa.

Hay que entender cómo concibe la doctrina liberal el término libertad, incluso en sus formas teóricas más avanzadas. Al respecto refiere Robert Alexy “...para la creación de una situación de libertad jurídica, se requiere tan solo una omisión del Estado, es decir una acción negativa. Para asegurar la libertad jurídica no se requiere ningún derecho a prestaciones sino un derecho de defensa." (Alexy, 1993, p. 215). Esta idea encierra dentro de sí una sutil contradicción, pues supone que la libertad solo se enmarca en la directa relación entre el ciudadano como titular del derecho-libertad y el Estado como sujeto de poder, jurídicamente obligado a la inacción y potencialmente vulnerador.

Esta tradicional división entre derechos de libertad y derechos de prestación, considera los primeros como esfera de abstención de intervención del Estado, exigibles judicialmente; mientras que los segundos son declaraciones políticas realizables según las posibilidades económicas de cada país, y nunca exigibles judicialmente. Para autores como Henry Shue y Von Hoof esta división es ficticia, y en su lugar proponen cuatro niveles de obligaciones estatales en el plexo de derechos fundamentales: una obligación de respetar, una obligación de proteger, una obligación de garantizar y una obligación de promover el derecho en cuestión.

Como plantean Abramovich y Curtis

Ninguno de estos niveles puede caracterizarse únicamente a través de las distinciones obligaciones negativas/obligaciones positivas, $u$ obligaciones de resultado/obligaciones de medio, aunque ciertamente las obligaciones de proteger, asegurar y promover parecen envolver un mayor activismo estatal, $\mathrm{y}$ por ende, un número mayor de obligaciones positivas o de conducta. (Abramovich y Curtis, 2004, p. 123).

La idea planteada por los autores se centra en la unidad entre los llamados derechos civiles y políticos (o derechos de libertad) y los derechos económicos, sociales y culturales (o derechos de prestación).

El autor de esta investigación asume la posición que relativiza la clásica división entre derechos de libertad y derechos de prestación, pues considera que todos los derechos están relacionados entre sí, y todos requieren de una intervención del Estado, aunque con grados diferentes de intensidad. En unos debe realizar una prestación directa para que se garantice el derecho, en otros debe crear condiciones para que los derechos se puedan realizar sin trabas, o incluso intervenir con sus órganos cuando hay vulneraciones ilegítimas. 
La vulneración de la libertad puede venir de cualquier órgano del Estado, individualmente considerado, o de un tercero, sea persona natural o jurídica. En este caso la libertad, para que se concrete como derecho-libertad debe suponer garantías para su titular, y estas garantías se consiguen generalmente mediante la intervención de algún "órgano de poder" del Estado, igual o diferente al ente vulnerador. De tal modo que la libertad no es solo un derecho a inhibir la intervención de ciertos poderes del Estado en una esfera particular de actuación, sino también la garantía de exigir a determinados órganos del Estado (Tribunales, Fiscalía, Defensoría del Pueblo, etc.) su intervención para que otros órganos del Estado, o los terceros, dejen de intervenir en la esfera de libertad de la que se es titular.

Hay autores que han propuesto subdivisiones muy interesantes, a la hora de abordar las libertades como derechos. Manuel García-Pelayo, retomando los criterios básicos de Carl Schmitt habla de:

Garantías de la esfera de la libertad individualista, que se dividen a su vez en: Derechos de libertad del individuo aislado; por ejemplo, la libertad de conciencia, la libertad personal, la propiedad privada, la inviolabilidad del domicilio. Derechos de libertad del individuo en relación con otros, como por ejemplo, la libre manifestación de opiniones, la libertad de discusión, la libertad de prensa, etc (García-Pelayo, 1984, p. 153).

El planteamiento de García-Pelayo supone, para los derechos de libertad del individuo en relación con otros, una expresión o esfera concreta del derecho de libertad en que este no se manifiesta en una simple relación bilateral ciudadano-Estado; sino en un complejo de relaciones en que existen por lo menos tres extremos: en uno el titular del derecho-libertad de prensa, en otro un sujeto vulnerador (puede ser un órgano del Estado, una persona natural, o una persona colectiva no estatal) y en el tercero el Estado actuando a través del órgano garante del ejercicio efectivo del derecho de libertad. Esta es una relación mínimamente tríadica entre el titular del derecho de libertad-sujeto vulnerador-sujeto garante.

Desde posiciones más progresistas se ha criticado el hecho de que la supuesta libertad de prensa se limita a libertad de iniciativa empresarial periodística para los dueños de medios, lo que no se expresa necesariamente en la libertad de expresión y derecho de información para todos los actores de la sociedad. Este planteamiento introduce en el debate la relación entre libertad de prensa formal y libertad de prensa material, así como la potencialidad real de que la libertad de prensa propicie el desarrollo de la libertad de expresión, y por lo tanto de una sociedad verdaderamente plural e informada. 
En línea con la anterior postura, María López de Ramón define la libertad de prensa como "la facultad de propagar libremente las informaciones y opiniones a través de los periódicos..." (López de Ramón, 2014, p. 11). Es significativo destacar que dicha autora concibe la libertad de prensa como un derecho fundamental, con la trascendencia que supone para el ordenamiento jurídico esta clasificación. Su definición no se concentra en la libertad empresarial para establecer periódicos, sino en la función social de estos en la difusión de información y opiniones.

Sin embargo, la propia definición de la libertad como derecho o facultad de hacer no supone un uso abusivo por su titular; la propia autora, refiriéndose al papel de los Estados en el establecimiento de los límites al ejercicio de este derecho plantea: "pese a ser plenamente reconocido por el gobierno correspondiente, en ningún caso supone un obstáculo para que éste imponga a sus ciudadanos determinadas restricciones con el fin de mantener la seguridad y el orden público fundamentales para garantizar la convivencia entre todos.” (López de Ramón, 2014, p. 11).

Lo anterior se esclarece con el doble contenido que supone la libertad de prensa como condición para que pueda desarrollarse el derecho a la información. En tal sentido expresa Javier Pérez Royo: "es un derecho doble: a comunicar libremente información y a recibir libremente información. Se trata, por tanto, de un derecho del que son titulares los diferentes medios de comunicación, es decir, los propietarios y trabajadores de los mismos, pero también todos los ciudadanos sin excepción...” (Pérez Royo, 1997, p. 301).Seguidamente señala que dicha libertad es el derecho de los propietarios de los medios y sus trabajadores a comunicar libremente información, y el de los ciudadanos a recibir dicha información, también de manera libre.

Para autores como Carmona Díaz de León el derecho a la información comienza a configurarse después de la segunda guerra mundial, y es expresión de la evolución de la libertad de prensa, la libertad de expresión, y el reconocimiento de los derechos de los periodistas. El derecho a la información es un paso de avance, pues en realidad contiene tres tipos de derecho de naturaleza diferente: dos asociados a los sujetos que intervienen en el proceso de informar, y otro relativo al acto en sí mismo. (Carmona Díaz de León, 2010, pp. 17 y 18). 
En cuanto a los sujetos, el derecho a la información contiene el derecho de los informadores, que consiste en:“...el derecho a que su trabajo no sea censurado; a investigar y a difundir la información u opinión que tenga; a contar con instrumentos técnicos para llevar al cabo su actividad; a la transmisión íntegra de su mensaje; a tener acceso a sus fuentes; al secreto profesional; y a la cláusula de conciencia." (Carmona Díaz de León, 2010, p. 18).

Según dicha autora, este derecho genérico contiene además, el derecho específico de los informados, consistente en el "derecho a recibir información; a seleccionar los medios por los cuales desea que esa información le sea transmitida; a la veracidad en la información; a preservar la honra y la intimidad; a requerir la imposición de responsabilidades legales; y al derecho de rectificación o respuesta." (Carmona Díaz de León, 2010, p. 18).

Obsérvese que la autora relaciona el derecho a la información, desde la perspectiva de los informados, con el derecho a la preservación de la honra, y asociado a ello los derechos de rectificación o respuesta. Se considera correcta esta postura, pues los derechos fundamentales expresan una interrelación y progresión, de lo que se deriva que unos ayudan a configurar a otros, limitándolos, desarrollándolos o ambas cosas a la vez.

Por último, la referida autora habla de los derechos asociados al acto de informar, el cual tiene carácter jurídico, e implica tanto derechos como obligaciones de periodistas y directivos de los medios. Lo anterior supone que “...en el supuesto de que se distorsione la realidad, estos sujetos están obligados a reparar los daños causados, lo que sitúa al afectado en la posición de solicitarles la aplicación de las responsabilidades ulteriores que entre otras, pueden incluir al derecho de rectificación o respuesta." (Carmona Díaz de León, 2010, p. 18).

En el contenido de los derechos asociados al acto de comunicar, como parte del derecho a la información, se reitera el carácter configurador y por ello delimitador de los derechos de rectificación o respuesta. El planteamiento evidencia la tendencia doctrinal a considerar dichos derechos como adscriptos, es decir, derechos que surgen y se instrumentan para garantizar otros derechos.

Otro elemento a considerar es que la información que propague el medio debe cumplir un requisito: ser razonablemente veraz, pues como afirma el Tribunal Constitucional español:

Cuando la Constitución requiere que la información sea veraz no está tanto privando de protección a las informaciones que puedan resultar erróneas, o sencillamente no probadas en juicio, cuanto estableciendo un específico deber de diligencia sobre el informador a quien se pueda y se deba exigir que lo que transmita como hechos haya sido contrastado con datos objetivos, 
privando así de la garantía constitucional a quien, defraudando el derecho de todos a la comunicación, actúe con menosprecio de la veracidad o falsedad de lo comunicado. El ordenamiento no presta su tutela a tal conducta negligente ni menos a quien comunica como hechos simples rumores, o lo que es peor, meras insinuaciones insidiosas. (Sentencia 15/93 del Tribunal Constitucional de España, de 1993).

La referida sentencia enuncia varios elementos para considerar la existencia o no de una veracidad razonable en la información propagada por el medio: a saber, un deber de diligencia por parte del que comunica, es decir, agotar razonablemente todos los recursos y medios disponibles a su alcance para llegar a la verdad; buscar, siempre que sea posible, datos objetivos; contrastar la información con esos datos objetivos para decantar la información que pueda ser falsa.

Este deber de diligencia trata de evitar la propagación de informaciones falsas, erróneas o imprecisas; dichas informaciones, cuando se refieren a cualidades o características de las personas sobre las que se informa, pueden provocar vulneraciones ilegítimas al honor de las miasmas; y por el impacto inmediato y masivo del medio, generar efectos irreversibles en cuanto a la consideración y estima a la que tienen derechos como ciudadanos.

También los medios difunden opiniones sobre hechos y personas, las que expresan juicios de valor sobre sus cualidades y características. Si no se garantiza que estas u otras personas presenten una opinión diferente sobre los criterios emitidos, con la misma inmediatez y masividad que garantiza el medio de comunicación, el punto de vista difundido será sesgado, y a la vez que se vulnera el honor de las personas implicadas se afecta el derecho a la información de los receptores, pues recibirán una información parcializada y no contrastada.

Los dos supuestos anteriores son típicas posibilidades de contradicción entre el derecho al honor y la libertad de prensa, en que el derecho a la información juega un papel configurador y delimitador de otros derechos. Una vez que no se ha garantizado la ponderación previa de los posibles derechos en colisión, desde previsiones pre conflictuales, se impone la solución en la vía judicial como última ratio. En ella los tribunales juegan un papel fundamental para garantizar el equilibrio entre derecho al honor y los derechos asociados a los medios de comunicación (libertad de prensa, libertad de expresión y derecho a la información), y con ello, su mayor realización posible. 


\section{POSIBLES COLISIONES ENTRE EL DERECHO AL HONOR Y LOS DERECHOS ASOCIADOS A LOS MEDIOS DE COMUNICACIÓN: LOS DERECHOS DE RESPUESTA Y RECTIFICACIÓN}

Uno de los problemas fundamentales que se presenta en la realización de los derechos fundamentales es la colisión. Esta se define, en general, como la contradicción entre la plena realización de un derecho y la plena realización de otro, cuyo despliegue implicaría una tensión entre valores jurídicos contrapuestos, y en cuya solución uno de los dos derechos debe ceder ante el otro.

Un caso típico de colisión es el que se presenta entre el derecho al honor y los derechos asociados a los medios de comunicación, principalmente la libertad de prensa, la libertad de expresión y el derecho a la información. Pero ¿Qué conductas de los medios de comunicación masiva son las que más frecuentemente provocan dicha colisión?

Al definir las formas más frecuentes de vulneración o intromisiones ilegítimas al honor Álvarez Tabío refiere

la divulgación de expresiones o la imputación de hechos concernientes a una
persona hechas de manera oral, escrita o gráfica, cuando la difamen o la
hagan desmerecer en la consideración ajena. Todo ataque ilegítimo de esta
esfera, implica el desmerecimiento en la consideración ajena como
consecuencia de expresiones proferidas en descrédito o menosprecio de
alguien o que fueren tenidas en el concepto público por afrentosas. (Álvarez
Tabío Albo, 2008, p. 46).

Como se aprecia la autora alude a un espectro amplio de situaciones en las que se pueden presentar las intromisiones ilegítimas o vulneraciones al honor personal; así como un amplio espectro de formas contentivas de dichas vulneraciones: la oral, la escrita o cualquier simbología gráfica.

A los efectos de la presente investigación estos supuestos se circunscriben a aquellas situaciones en las que intervienen los medios de comunicación, como principal vehículo o soporte de divulgación de las expresiones, informaciones u opiniones potencialmente vulneradoras del honor.

De tal manera, haciendo una deducción lógica de los supuestos generales y su integración a las características ya estudiadas de los medios masivos de comunicación, se pueden identificar tres formas concretas de vulneración o intervenciones ilegítimas en el honor: 
1-la divulgación mediática de expresiones potencialmente deshonrosas,

2-la divulgación mediática de informaciones potencialmente deshonrosas, y

3-la divulgación mediática de opiniones potencialmente deshonrosas.

La resolución de estas contradicciones o colisiones depende de la postura teórica que se asuma al respecto. Para autores como Robert Alexy el análisis está sujeto a considerar si los derechos contrapuestos se encuentran regulados en una norma regla, una norma principio o una norma valor.

El autor significa una diferencia cualitativa entre reglas y principios. En cuanto a la falta de coherencia en los ordenamientos jurídicos, en el caso de los últimos, se aprecia la llamada colisión de principios, mientras que para las primeras se constata un conflicto de reglas. El método o procedimiento de solución en ambos casos es bien diferente.

Para Alexy, el conflicto de reglas solo puede ser solucionado introduciendo una cláusula de excepción, que elimina el conflicto, o declarando no válida una de las reglas (Alexy, 1993, p. 88). Estas son las únicas formas mediante las cuales se puede eliminar unos juicios de deber ser contradictorios, que expresan consecuencias jurídicas diferentes, confrontadas entre sí, para un mismo supuesto jurídico, ya sea de hecho o de derecho.

Para los principios el profesor de Kiel propone otro método de solución, el cual expone de la siguiente manera:

Cuando dos principios entran en colisión - tal como es el caso cuando según un principio algo está prohibido y, según otro principio, está permitidouno de los dos principios tiene que ceder ante el otro. Pero, esto no significa declarar inválido al principio desplazado ni que en el principio desplazado haya que introducir una cláusula de excepción. Más bien lo que sucede es que bajo ciertas circunstancias uno de los principios precede al otro. Bajo otras circunstancias, la cuestión de la precedencia puede ser solucionada de manera inversa. Esto es lo que se quiere decir cuando se afirma que en los casos concretos los principios tienen diferente peso y que prima el principio con mayor peso. (Alexy, 1993, p. 88).

Esto le permite afirmar que los conflictos de reglas se llevan a cabo y se solucionan mediante la determinación de la validez; mientras que la colisión de principios se resuelve en la dimensión del peso, es decir, determinando el de mayor peso para el caso concreto, siendo este el que debe prevalecer para dicha situación particular.

La solución en la colisión de principios viene dada por lo que Robert Alexy llama ponderación de bienes, sustentada en la "Ley de colisión" (Alexy, 1993, p. 90). Esta solución se define como “...un enunciado de preferencia condicionado que, de acuerdo con la Ley de colisión, surge de una regla diferenciada de decisión" (Alexy, 1993, p. 166). La colisión de 
principios se expresa como una relación de tensión entre intereses opuestos, y su solución consiste en ponderar cuál de los intereses, abstractamente del mismo rango, posee mayor peso en el caso concreto.

La denominada "Ley" supone el establecimiento de una relación de precedencia condicionada entre los principios en colisión. Como propone Alexy: "La determinación de la relación de precedencia condicionada consiste en que, tomando en cuenta el caso, se indican las condiciones bajo las cuales un principio precede al otro. Bajo otras condiciones, la cuestión de la precedencia puede ser solucionada inversamente.” (Alexy, 1993, p. 92).

El planteamiento en sí es complejo para el caso de la colisión del derecho al honor con la libertad de expresión. Si se entendiera el derecho fundamental al honor como norma principio, una de las posibilidades que da el profesor de Kiel para los derechos fundamentales, se estaría en una situación excepcional de precedencia incondicionada, siempre que el honor se conciba en el ámbito de la dignidad humana.

Alexy plantea que para todos los supuestos de determinación de la relación de precedencia deben establecerse las condiciones que determinan la regla de ponderación, lo que permite hallar la norma principio que debe prevalecer para ese caso concreto; sin embargo, advierte que la única excepción a la aplicación de la regla de ponderación es cuando uno de los principios en colisión es la dignidad humana. Esto provocaría una precedencia absoluta o incondicionada que haría prevalecer siempre cualquier derecho asociado a la dignidad humana, si es uno de los que entra en colisión.

De lo planteado se concluye que, en una colisión o conflicto de normas, en que una de las normas proteja el derecho al honor, se podrían dar tres soluciones teóricas diferentes: primero, que el derecho fundamental al honor sea considerado una norma regla de derecho fundamental, y que por lo tanto lo que pueda apreciarse sea un conflicto de reglas, que se soluciona introduciendo una cláusula de excepción, que elimina el conflicto, o declarando no válida una de las reglas.

El segundo supuesto es un conflicto o colisión de normas de derecho fundamental en que una de las normas sea de derecho al honor, y que el derecho fundamental al honor se considere una norma principio de derecho fundamental con identidad propia, no asociada a la dignidad humana. En este caso la solución sería establecer una relación de precedencia condicionada, mediante una ponderación de derechos en conflicto, para determinar qué 
derecho debe prevalecer en el caso concreto. Aquí son importantes las condiciones en que se desarrolla el conflicto, para la aplicación de la "Ley de ponderación".

El tercer supuesto es un conflicto o colisión de normas de derecho fundamental en que una de las normas protege el derecho al honor, y que el derecho fundamental al honor se considere una norma principio de derecho fundamental dependiente o asociada a la dignidad humana. En este caso el principio de la dignidad humana es considerado una excepción, por lo que no se sujeta a la regla de la relación de precedencia condicionada, sino a la de precedencia incondicionada (Alexy, 1993, p. 92). En este caso particular siempre el principio que debe prevalecer es el asociado a la dignidad humana. Aquí las condiciones en que se desarrolla el conflicto no son importantes, pues el principio que debe prevalecer está predeterminado.

Una apreciación integral de la regulación y protección efectiva del derecho al honor supone una visión transversal de este derecho para todo el ordenamiento jurídico, partiendo de la Constitución e irradiando a las demás ramas del Derecho. Esta visión propone que el derecho fundamental al honor pueda gozar de un desarrollo tal que se exprese en las diferentes ramas del Derecho como norma regla, como norma principio relativamente independiente y como norma principio asociada a la dignidad humana.

Sin embargo, las reglas de ponderación e inaplicación, como métodos de resolución de las colisiones de derechos tienen una limitación: son aplicables solo a colisiones en curso, en casos concretos, en que generalmente interviene el órgano jurisdiccional en la fase final del conflicto iusfundamental. Su eficacia para prevenir conflictos potenciales es cuestionable.

La previsión de colisiones entre el derecho al honor y los derechos asociados a los medios de comunicación (libertad de prensa, de expresión y derecho a la información) se orienta más a estipular ciertas garantías en los ordenamientos jurídicos, mediante la instrumentación de derechos adscriptos, en particular los derechos de respuesta y rectificación.

Estos derechos previenen posibles colisiones, o anticipan la resolución del conflicto, sin que éste tenga que llegar a la vía judicial para su resolución, como ocurre con las reglas de ponderación e inaplicación. Los derechos adscriptos de respuesta y rectificación se convierten en límites garantistas ante posibles vulneraciones del honor, provocadas por abusos en el ejercicio de los derechos asociados a los medios de comunicación. 
Para autores como Aguirre Nieto el derecho de rectificación es la facultad que tiene toda persona de solicitar la rectificación de hechos $\mathrm{u}$ opiniones que la aludan, por considerarlos inexactos y que puedan perjudicarla. Se ha impuesto como visión más avanzada que la rectificación se hará en el mismo medio de comunicación, de manera gratuita para el que la solicita, y se realizará en el número o emisión más próxima y posterior a aquella que ha generado el ejercicio del derecho. (Aguirre Nieto, 2003, pp. 56 y 57).

Pero ¿Cómo aparecen estos derechos y qué finalidad persiguen? Para algunos autores (Aguirre Nieto, 2003, pp. 56 y 57) los antecedentes hay que buscarlos en el proyecto francés de Ley de prensa de 1789, así como en las leyes de prensa francesas de 22 de marzo de 1822 , de 29 de julio de 1881, y de 29 de julio de 1982, relativa a los medios audiovisuales.

Desde el punto de vista del derecho internacional el derecho de rectificación aparece, con identidad propia, en la Convención del Derecho Internacional de Rectificación de la ONU, de 16 de diciembre de 1952, y que entró en vigor el 24 de agosto de 1962. Ésta tiene como fin evitar que la difamación de personas o Estados ponga en peligro la paz y la colaboración internacional.

En tal sentido, el artículo 2.1 de dicho tratado expresa:

Los Estados Contratantes convienen en que, cuando un Estado Contratante alegue que determinado despacho informativo, capaz de perjudicar sus relaciones con otros Estados o su prestigio o dignidad nacionales, es falso o tergiversado y tal despacho informativo haya sido transmitido de un país a otro por corresponsales o agencias de información de un Estado Contratante o no contratante, y publicado y difundido en el extranjero, aquel Estado podrá presentar su versión de los hechos (denominada en adelante "comunicado") a los Estados Contratantes en cuyos territorios haya sido publicado o difundido. Al mismo tiempo, se enviará un ejemplar del comunicado al corresponsal o a la agencia de información interesados, a fin de que tal corresponsal o agencia de información pueda rectificar el despacho informativo de que se trate. (ESPAÑA. Convención sobre el Derecho Internacional de Rectificación. Disponible en www.unhchr.ch/ spanish/html/menu3/b/i ilocor_sp.htm Consultado el 18 de mayo de 2017).

Como puede apreciarse, se trata de una variante de rectificación que trasciende a las relaciones entre los Estados, en la que intervienen agencias informativas, personas y al menos un Estado reclamante.

Autores como Carmona Díaz de León critican el carácter limitado de esta Convención, en lo relativo a las sanciones a aplicar a los Estados que no acojan la reclamación: estar sujetos a un tratamiento recíproco del Estado reclamante, estar sujetos a la elevación de un informe crítico ante el Secretario General de la ONU por parte del Estado reclamante, y estar 
sujetos a que se tramite una demanda ante la Corte Internacional de Justicia. (Carmona Díaz de León, 2010, pp. 185 y 186).

Debe destacarse que en el contexto hemisférico el primer documento que recoge de manera explícita el derecho de rectificación es la Convención Americana sobre Derechos Humanos, que se adoptó el 22 de noviembre de 1969, y que entró en vigor el 18 de julio de 1978. Esta estipula en su artículo 14:

1. Toda persona afectada por informaciones inexactas o agraviantes emitidas en su perjuicio a través de medios de difusión legalmente reglamentados y que se dirijan al público en general tiene derecho a efectuar por el mismo órgano de difusión su rectificación o respuesta en las condiciones que establezca la ley.

“2. En ningún caso la rectificación o la respuesta eximirán de las otras responsabilidades, legales en que se hubiese incurrido.

"3. Para la efectiva protección de la honra y la reputación, toda publicación o empresa periodística, cinematográfica, de radio o televisión, tendrá una persona responsable que no esté protegida por inmunidades, ni disponga de fuero especial. (Convención Americana Sobre Derechos Humanos. https://

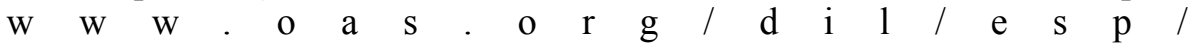
tratados_b32_convencion_americana_sobre_derechos_humanos.htm).

Desde el punto de vista teórico, la tradición francesa introduce una disquisición que todavía no se ha resuelto del todo. Ellos abordan un concepto genérico de rectificación, que luego se concreta en un derecho específico de rectificación (droit de rectification) y un derecho de réplica (droit de réponse).

El primero contiene la obligación del medio de publicar las rectificaciones hechas por los funcionarios públicos derivadas de un acto de su función; mientras que segundo es el derecho que tiene toda persona nombrada en un periódico a que se inserte su respuesta en lo referido a dicha alusión. Estas inserciones deben ser gratuitas y hacerse con la mayor celeridad. Cabe señalar que la doctrina y la legislación francesas, para la instrumentación y ejercicio de estos derechos, no distingue entre hechos y opiniones, y sí en quienes ejercen el derecho: si es un sujeto general o un funcionario público.

La doctrina española, sin embargo, si distingue entre hechos y opiniones para determinar si se trata de una rectificación o de una réplica. Para dichos autores, derecho de rectificación procede cuando se trata de intentar reducir la narración de los hechos a la exactitud de lo ocurrido; mientras la réplica procede cuando se intenta argüir algo contra los argumentos o las respuestas del otro. (Carmona Díaz de León, 2010, p. 23).

Esta disquisición sobre si pueden separarse o no hechos y opiniones emitidas por los medios obedece a dos posiciones teóricas: el grupo de teorías monistas, que considera 
inseparable hechos y opiniones, y las teorías dualistas, que consideran separable los hechos de las opiniones. Se considera el segundo grupo de teorías más adecuado al objeto que se investiga, pues permite un correcto tratamiento teórico y legal al honor, frente a posibles vulneraciones de los medios de comunicación.

Este abordaje dualista concibe que los hechos informados por los medios deben ser veraces. A tal efecto, Apreza Salgado, coincidiendo con el Tribunal Constitucional español, expresa que la veracidad es una cualidad de la información y, por tanto:

requiere que el emisor de la información compruebe la información con
prudente diligencia, contrastándola con datos objetivos, de tal forma que la
veracidad es sinónimo de mínimo cuidado y diligencia en la búsqueda de lo
cierto, privando de la garantía constitucional al emisor que actúe con
menosprecio a la veracidad o falsedad de lo comunicado, debido a que el
derecho constitucional no ampara ni la información que se sabe inexacta por
quien la transmite ni la difundida sin contraste alguno con los datos
objetivos, evitando que el emisor transmita como hechos verdaderos simples
rumores carentes de toda constatación, meras invenciones o insinuaciones.
(Apreza Salgado, 1994, p. 27).

Sin embargo, en el caso de las opiniones se exige que sean contrastadas, no tanto con la verdad material como con otros puntos de vista; pues aquí de lo que se trata no es tanto de la objetividad o veracidad de lo informado, como de la posibilidad de recibir otros juicios de valor, otros puntos de vista.

La cualidad de contrastación de las opiniones incide considerablemente en la calidad de la participación de los ciudadanos en los asuntos públicos, pues la participación democrática “...dependerá de la información que tengan a su disposición -a fin de estar en la posibilidad de ponderar opiniones diversas y aún contrapuestas-, la cual contribuye de manera libre a la formación de un criterio propio.” (Apreza Salgado, 1994, p. 27). Esta es una forma legítima de formarse opiniones, incluso sobre el honor de personas e instituciones.

El carácter abierto de los medios para los receptores expresa una posibilidad de acceso potencialmente ilimitado de la población a la información publicada, lo que a su vez implica la irreversibilidad de un efecto mediático lesivo al honor. Esta posibilidad requiere de una garantía de respuesta rápida para atenuar tales efectos, que implica publicar con la mayor celeridad posible una respuesta a la publicación lesiva, que a su vez garantice un público similar.

La respuesta, como garantía del derecho al honor frente a los medios de comunicación, debe implicar la oportunidad de ofrecer un punto de vista diferente sobre la opinión emitida 
por el medio, y que contribuyó o pudo contribuir a la formación de una opinión pública lesiva al honor de alguna persona o grupo de personas.

En el sentido antes señalado, el derecho a la información implica el derecho que tienen los receptores del mensaje a contar con una opinión diferente, con otro punto de vista o juicio de valor, desde la perspectiva del o de los sujetos cuyo honor fue vulnerado; así como el derecho del sujeto o sujetos, cuyo honor está en juego, a emitir su punto de vista discrepante sobre el punto controvertido, en las condiciones en que lo hizo previamente el medio. Este es el caso típico en que está presente el derecho de respuesta.

Pero el desarrollo de los medios de comunicación ha tenido un impacto significativo en el desarrollo de la legislación y de las teorías jurídicas que fundamentan su existencia. Particular importancia reviste la aparición y posterior evolución de la libertad de prensa. La consolidación de dicha libertad marcha al paralelo, incluso en ocasiones a mayor "velocidad", que el referido derecho al honor; como se ha dicho, ambos derechos muestran en su despliegue una especial potencialidad para entrar en contradicción. En el segundo capítulo se ofrecerán los presupuestos que deben informar la instrumentación de los derechos de respuesta y rectificación, como garantías de protección del derecho al honor frente a actuaciones lesivas de los medios de comunicación.

\section{CONCLUSIONES}

El derecho al honor es una institución de carácter histórico y de significado variable, que ha estado asociada al derecho que todo ser humano tiene a su consideración, estima, fama, dignidad, reconocimiento y respeto personal y social. En el campo del Derecho Constitucional se ha enfocado como derecho fundamental, configurándose como honor objetivo (estima y consideración que la sociedad tiene de uno) y como honor subjetivo (estima y consideración que uno tiene de sí mismo).

Las teorías de los medios de comunicación abordan diferentes aristas del proceso de comunicación de masas, siendo las más trascendentes al estudio de este objeto, las teorías de los efectos y las teorías normativas de los medios de comunicación. 
Las teorías de los efectos y las teorías normativas de los medios de comunicación llamadas de "responsabilidad", "democrática" y "de participación comunitaria” justifican una regulación de los efectos lesivos de los medios, mediante la creación de límites formales, como garantías.

El despliegue de los derechos asociados a los medios de comunicación (libertad de expresión y prensa, y derecho a la información) ha creado, históricamente, situaciones de colisión con el derecho al honor, propiciando vulneraciones a este, como la la divulgación mediática de expresiones potencialmente deshonrosas, la divulgación mediática de informaciones potencialmente deshonrosas, y la divulgación mediática de opiniones potencialmente deshonrosas (derivadas de vicios de veracidad o de no contrastación), contribuyendo a formar estados de opinión injustamente lesivos al honor de personas e instituciones.

La colisión los derechos asociados a los medios de comunicación y el derecho al honor se ha resuelto mediante reglas de ponderación e inaplicación, en la vía judicial, luego de la aparición del conflicto; y a través de garantías previsoras, como la instrumentación de los derechos adscriptos de respuesta y rectificación.

\section{REFERENCIAS BIBLIOGRÁFICAS}

ABRAMOVICH, Víctor; CURTIS, Christian. Los derechos sociales como derechos exigibles, 2da edición. Madrid: Trotta, 2004, 123 p.

AGUIRRE NIETO, Marisa. El derecho a la información como ciencia. BEL MALLEN, Ignacio; LORETO CARREDOIRA, Alfonso (coordinadores). Derecho a la información. Madrid: Ariel, 2003, pp. 56 y 57.

ALBERDI ARÁOZ, Juan Bautista. Obras selectas, T-XVII. Buenos Aires: Asociados Editores, 1920, 230 p.

ALEXY, Robert. Teoría de los derechos fundamentales. Madrid: Centro de Estudios Constitucionales, 1993, pp. 88-215.

ÁLVAREZ TABÍO ALBO, Ana María. Los derechos al honor, la intimidad personal y familiar y la propia imagen como límites a las libertades de información y de expresión, Tesis presentada para obtener el grado de Doctora en Ciencias Jurídicas, Universidad de La Habana. La Habana: s/e, 2008, 109 p. 
APREZA SALGADO, Socorro. Veracidad y pluralismo informativo en el medio televisivo: una tarea pendiente. Salamanca: Ediciones Universidad de Salamanca, 1994, 27 p.

BADENI, Gregorio. Tratado de Derecho Constitucional, Tomo 1, 2da. Edición. Buenos Aires: La Ley, 2006, 442 p.

BLAS GUERRERO, Andrés; GARCÍA COTARELO, Ramón. Teoría del Estado y Sistemas Políticos. Parte General Teoría del Estado (I). La Habana: s/e, s/f, 209 p.

CARMONA DÍAZ DE LEÓN, Eugenia Paola. EI derecho de rectificación en México, Tesis presentada para obtener el grado de Doctora en Derecho, Universidad Nacional Autónoma de México. México: s/e, 2010, pp. 17-186.

COLECTIVO DE AUTORES. Derecho Penal Especial. Tomo II. La Habana: Editorial Félix Varela, 2005, $171 \mathrm{p}$.

ECHEVARRÍA ESPINOSA, Esteban. Dogma Socialista. La Plata: Universidad Nacional de La Plata, 1940, 165 p.

ESPAÑA. Convención Americana Sobre Derechos Humanos. Disponible en https:// www.oas.org/dil/esp/tratados_b32_convencion_americana_sobre derechos humanos.htm Consultado el 25 de junio de 2017.

ESPAÑA. Convención sobre el Derecho Internacional de Rectificación. Disponible en www.unhchr.ch/spanish/html/menu3/b/i_ilocor_sp.htm Consultado el 18 de mayo de 2017.

ESPAÑA. Sentencia del Tribunal Constitucional de España 15/1993, de 18 de enero de 1993.

ESTADOS UNIDOS DE AMÉRICA. La Constitución de los Estados Unidos de América, con nota explicativa. Washington D.C.: Departamento de Estado de los Estados Unidos, 1999, 45 p.

GARCÍA FAJARDO, J.C.: Comunicación de masas y pensamiento político. Madrid: Editorial TECNOS, S.A., 1992, 23 p.

GARCÍA-PELAYO, Manuel. Derecho constitucional comparado. Madrid: Alianza Editorial S.A., 1984, 153 p.

LÓPEZ DE RAMÓN, María. La construcción histórica de la libertad de prensa. Madrid: Universidad Carlos III, 2014, 11 p.

LÓPEZ GUERRA, Luis et al (Org.). Derecho Constitucional. Volumen I. El ordenamiento constitucional. Derechos y deberes de los ciudadanos. Valencia: Tirant lo Blanch, 2000, pp. 73-146.

MARTÍN DE LA GUARDIA, R.: Cuestión de tijeras. La censura en la transición a la democracia.Madrid: Síntesis, 2008, 10 p.

MCQUAIL, Danis. Introducción a la teoría de la comunicación de masas. Barcelona: Ediciones Paidós, 1985, pp. 26-43.

PALACIOS, Alfredo. EI delito de opinión y la tradición argentina. Buenos Aires: s/e, 1939, $163 \mathrm{p}$.

PERÉZ LUÑO, Enrique. Los Derechos Fundamentales. Madrid: Editorial TECNOS, 1994, $44 \mathrm{p}$. 
PÉREZ ROYO, Javier. Curso de Derecho Constitucional. Madrid: MARCIAL PONS, EDICIONES JURÍDICAS Y SOCIALES S.A. (Cuarta Edición), 1997, 301 p.

ROSENTAL, M. y IUDIN, P.: Diccionario Filosófico. La Habana: Editora Política, 1981, 223 p.

VALDÉS DÍAZ, Caridad Del Carmen. Derecho Civil Parte General. La Habana: Editorial Félix Varela, 2005, pp. 134-145.

VILLABELLA ARMENGOL, Carlos. Los derechos humanos. Consideraciones teóricas de su legitimación en la Constitución cubana. PRIETO VALDÉS, Martha (Compiladora).Selección de textos constitucionales. Primera Parte. La Habana: ENPES, 1991, 91 p. 